\title{
Numerical analyses of a tunnel in London clay using different constitutive models
}

D. Mašín

Charles University and Czech Academy of Sciences, Prague, Czech Republic

I. Herle

Institute of Geotechnical Engineering, TU Dresden, Germany

ABSTRACT: The paper presents results of FE simulations of the Heathrow Express trial tunnel in London clay. The influence of constitutive equations on numerical predictions is evaluated and compared with field observations. The equations include two traditional models (Mohr-Coulomb, Modified Cam-Clay) and four models of different complexity (isotropic and anisotropic nonlinear elasticity with perfect plasticity, combined isotropic and kinematic hardening plasticity, and hypoplasticity). Nonlinear elasticity and hypoplasticity with intergranular strains come close to the observed behaviour whereas other models give non-realistic predictions due to an unsatisfactory behaviour in the small strain region.

\section{INTRODUCTION}

Underground constructions offer the only possibility for a further urban development in a dense network of buildings and transportation ways. Prediction of deformations induced by tunnelling processes is therefore becoming one of the major tasks for geotechnical engineers. Interaction between existing structures and underground openings is a complex action where the soil/rock behaviour represents only one of many aspects of the tackled problem. Nevertheless, a realistic model of the ground is an essential prerequisite for the estimation of the magnitude and distribution of deformations.

The paper presents results of finite element analyses of the Heathrow Express trial tunnel. The shotcrete technology for the tunnelling in London clay has not been widely applied until then and this trial tunnel with an extensive monitoring programme provided an opportunity to gain data and experience. A comprehensive database of laboratory results on London clay enabled the calibration and the subsequent application of several constitutive models of a different quality and extent. The obtained results allow recommendations on the selection of appropriate models.

\section{CONSTITUTIVE MODELS}

The present state in the constitutive modelling of soils is confusing. Besides a few well-established equations a large number of constitutive mod- els has been proposed, the properties of which are difficult to judge. In this paper, two traditional models (Mohr-Coulomb, Modified CamClay) were supplemented by four further models of different complexity (isotropic and anisotropic nonlinear elasticity with perfect plasticity, combined isotropic and kinematic hardening plasicity, and hypoplasticity).

Mohr-Coulomb model (MC), a linear elasticperfectly plastic model, is perhaps the most popular constitutive equation in geomechanics. Its basic parameters like Young modulus $E$ or friction angle $\varphi$ are being considered as physically sound soil quantities. However, they are not true soil constants which makes the calibration and the application of this model difficult and rather userdependent.

A simple non-linear elastic model (NLE) combined with the Mohr-Coulomb failure criterion has been used. It predicts degradation of shear and volumetric stiffness with deformation and is suitable for problems with monotonous stress paths. Shear modulus $G$ and bulk modulus $K$ are related to the second invariant of deviatoric strain tensor $\epsilon_{s}$ and to volumetric strain $\epsilon_{v}$ by

$G= \begin{cases}G_{0} & \text { if } \quad \epsilon_{s} \leq R \\ G_{0}\left(\frac{R}{\epsilon_{s}}\right)^{\gamma} & \text { if } \quad \epsilon_{s}>R\end{cases}$

$K=\left\{\begin{array}{lll}K_{0} & \text { if } & \left|\epsilon_{v}\right| \leq R \\ K_{0}\left(\frac{R}{\left|\epsilon_{v}\right|}\right)^{\delta} & \text { if } & \left|\epsilon_{v}\right|>R\end{array}\right.$ 
Here $G_{0}$ and $K_{0}$ are initial shear and bulk moduli:

$\frac{G_{0}}{p_{r}}=A\left(\frac{p}{p_{r}}\right)^{n}$

$K_{0}=\frac{p}{\kappa^{*}}$

$p_{r}$ is a reference stress $1 \mathrm{kPa} . A, n, \kappa^{*}, R, \gamma$ and $\delta$ are model parameters.

The next model (AI NLE) combines the nonlinear elastic model with cross-anisotropic elasticity (Graham and Houlsby, 1983). The anisotropic formulation introduces the coupling between volumetric strain and shear stresses (or shear strains and mean stress, respectively). Only one additional parameter $\alpha$, which takes into account the ratio between the stiffnesses in the vertical and horizontal directions, is needed.

Modified Cam-Clay model (CC) has been used as proposed by Roscoe and Burland (1968). The triaxial stress invariants were modified for general stress conditions.

A combined isotropic-kinematic hardening plasticity model (3SKH) published by Stallebrass and Taylor (1997) represents an advanced complex material equation. Through the incorporation of three characteristic surfaces in the stress space it is capable to consider the role of the recent stress history on soil stiffness.

The hypoplastic model for soils with low friction angles (Hypo IS) proposed by Herle and Kolymbas (2004) was enhanced by the intergranular strain concept (Niemunis and Herle, 1997). This allows to include the recent deformation history as well. A slight modification of the model has been applied: Eq. (A.10) from Herle and Kolymbas (2004) has been replaced by

$\xi=\left\langle\frac{\sin \varphi_{c}-\sin \varphi_{m}}{\sin \varphi_{c}}\right\rangle^{p_{\xi}}$

with $p_{\xi}$ being the additional model parameter. It can better control the decay of the factor $\xi$ with increase of the mobilised friction angle $\varphi_{m}$ (the original model used $p_{\xi}=1$ ). Consequently, a high quasi-elastic stiffness in anisotropic stress states can be modelled (Mašín, 2005).

\section{CALIBRATION AND ELEMENT TESTS}

The determination of material parameters (calibration) is always related to the particular model formulation. Some aspects of the soil behaviour cannot be considered by all models. Still, due to a large number of data from laboratory element tests, a simultaneous approximation of several experimental outputs with model predictions was attempted. Examples of the measured and predicted $G-\epsilon_{s}$ curves, $q / p^{\prime}-\epsilon_{s}$ curves and normalised stress paths are shown in Figures 1,2 and 3. A perfect agreement cannot be expected because of very different model frameworks.

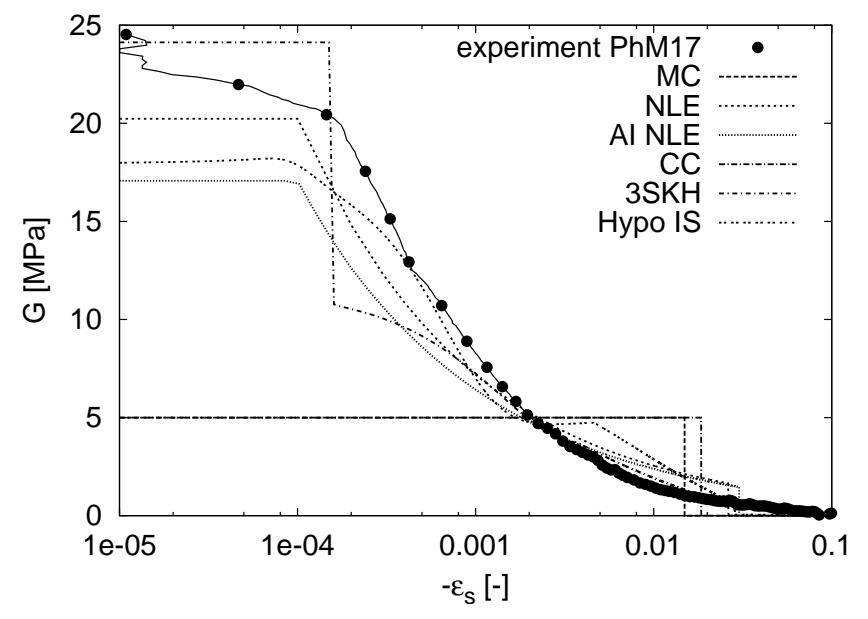

Figure 1. $G-\epsilon_{s}$ curves predicted by different models.

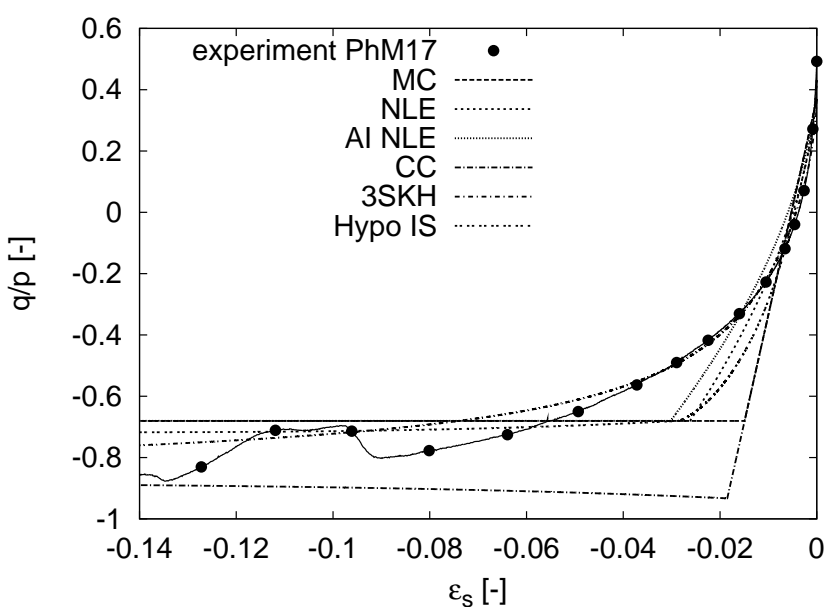

Figure 2. Stress-strain curves predicted by different models.

Morover, the performance of advanced models depends on initial values of their state variables. The initial conditions (correct alignment of kinematic surfaces) for the simulation of shear stages of laboratory experiments using the 3-SKH model were found by simulation of the entire stress history of the corresponding laboratory tests (see Section 4.). The same initial values of the relevant state parameters were also applied for the Modified Cam-Clay model.

All model parameters used in the finite element simulations are summarized in Appendix.

\section{INITIAL STATE}

Initial conditions prior to the simulation of the tunnel excavation may significantly influence results of analyses. However, a direct measurement of stresses in the ground is almost impossible. Therefore, the approach adopted in this work reproduces numerically the whole stress history of 


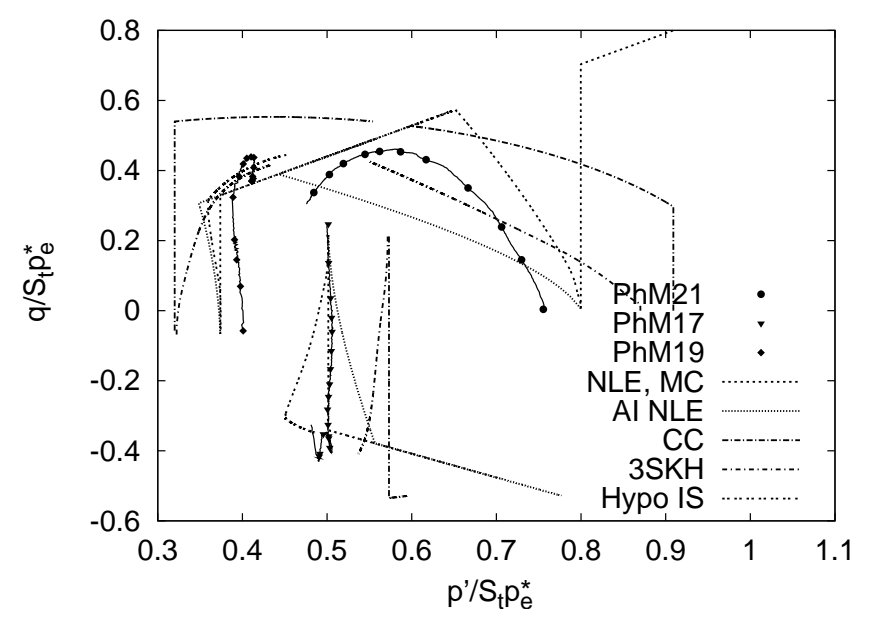

Figure 3. Stress paths normalised by the equivalent pressure $p_{e}^{*}$ and sensitivity $S_{t}\left(S_{t}\right.$ takes into account the different behaviour of natural and reconstituted samples).

the London clay massive. It consists of "oedometric" $\left(K_{0}\right)$ loading up to the vertical effective pressure $1500 \mathrm{kPa}$ at the current surface (sedimentation), $K_{0}$ unloading back to $0 \mathrm{kPa}$ (erosion), and reloading to $100 \mathrm{kPa}$ (sedimentation of gravel deposits). A so-called AI3-SKH model (Mašín, 2003) has been used for this simulation. It has been shown that the AI3-SKH model can better simulate stress states (Figure 4) and the corresponding porosity from $K_{0}$ loading and unloading paths than the simpler 3-SKH model.

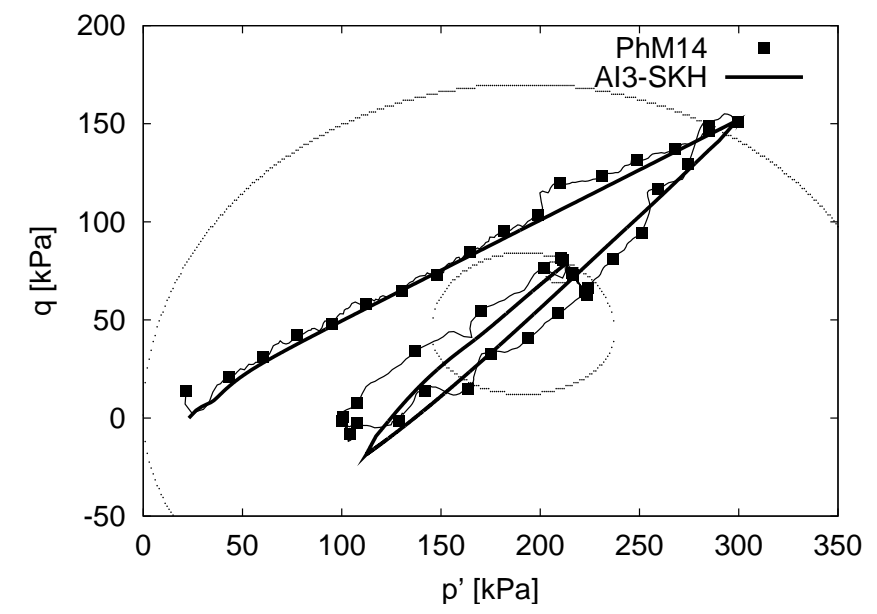

Figure 4. Simulation of $K_{0}$ loading and unloading experiment using the AI3-SKH model.

The stress history of London clay stratum predicted by the AI3-SKH model in a depth of the tunnel centreline is shown in Figure 5. Initial coefficient of the earth pressure at rest before simulation of the excavation stage was $K_{0}=1.45$.

The advanced constitutive models (Hypo IS and 3SKH) take into account the influence of the recent history on soil behaviour. However, as shown e.g. by Clayton and Heymann (2001), sufficiently long creep period erase these effects (laboratory experiments yield high small-strain stiffness for

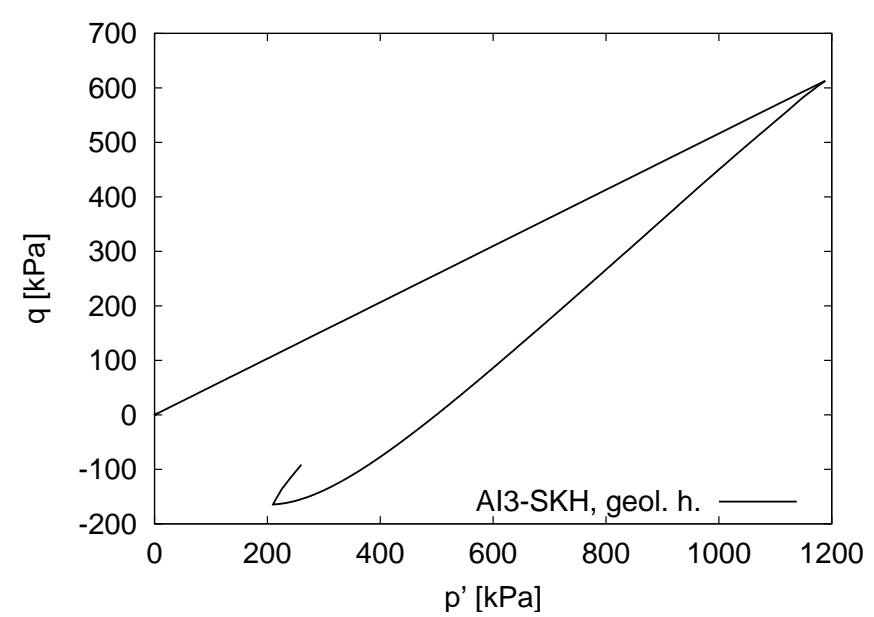

Figure 5. Stress history of the London clay stratum simulated by the AI3-SKH model.

loading in different directions). Erasing the effects of the recent deformation history was included into the present analyses by centering the kinematic surfaces about the current stress state $(3 \mathrm{SKH})$ and setting the values of the components of the intergranular strain tensor to zero (Hypo IS), respectively. Nevertheless, additional simulations have subsequently shown, that these effects of the geological history do not significantly influence results of finite element analyses.

Effects of the natural structure have been considered in the models with porosity as a state variable (CC, 3SKH and Hypo IS) by increasing the size of the state boundary surface applying the sensitivity framework (Cotecchia and Chandler, 2001), as discussed in detail by Mašín (2004).

\section{FINITE ELEMENT SIMULATIONS}

Plane-strain finite element simulations have been performed with the FE package Tochnog (www.feat.nl). This code enables an implementation of various constitutive models via user subroutines. A coupled (deformation-groundwater flow) formulation was used for all simulations.

Preliminary calculations checked the influence of the mesh density (352-1408 elements in a structured or unstructured mesh, respectively) and of the element type (triangle or quadrilateral elements with linear interpolation). The influence of these factors on the results has been shown to be of a minor importance.

The plane-strain simulation requires a severe simplification of the excavation process. In the first step, a common way is to reduce the nodal forces along the tunnel lining proportionally to the original geostatic stress. This reduction substitutes three-dimensional arching effects at the tunnel face. In the second step, the elements of the tunnel lining are activated and the elements inside the tunnel profile are erased. The reduction 


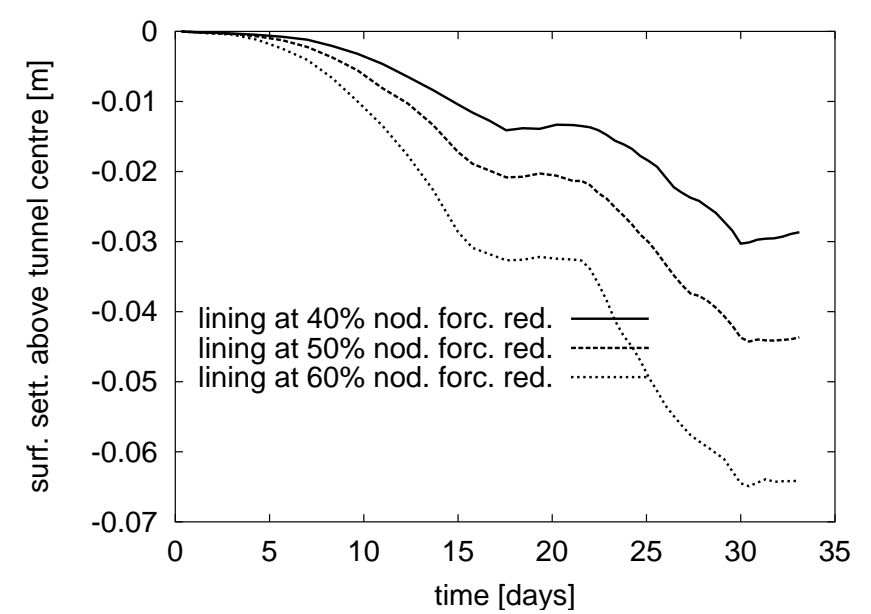

Figure 6. The influence of parameters used in the plainstrain simplification of the NATM method (simulated by Hypo IS model).

of the nodal forces in the first step is arbitrary and has a decisive impact on the calculated deformations (Figure 6). Consequently, only a qualitative comparison with the measured field values ("experiment") is meaningful.

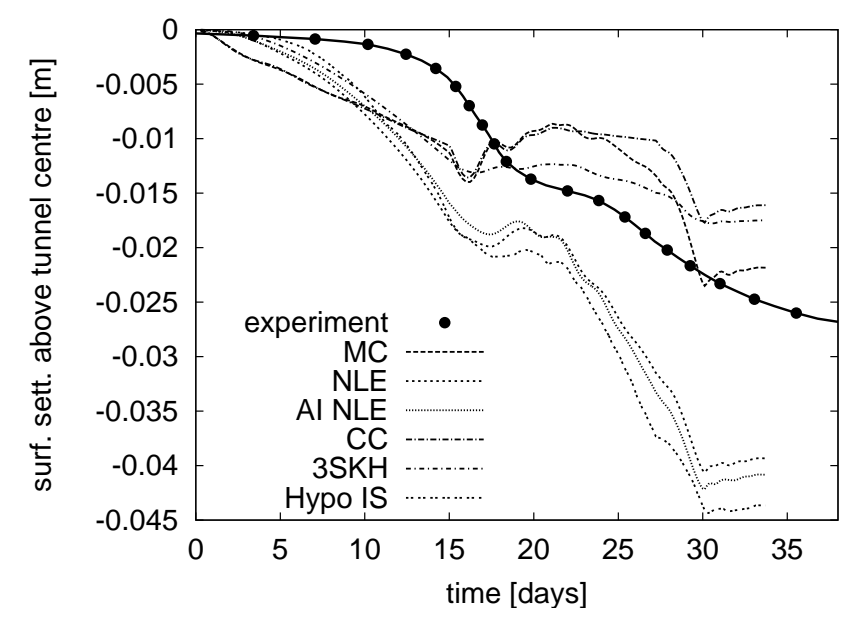

Figure 7. Surface settlement above tunnel centreline calculated by different constitutive models.

The development of the surface settlement above the tunnel centreline with time obtained with different soil models is shown in Figure 7. The nonsmooth shape of the settlement curve with time is due to two excavation stages of the tunnel profile (first the left and then the right side). Corresponding horizontal deformations along the vertical cross-section in a $6.3 \mathrm{~m}$ distance from the tunnel centreline are depicted in Figure 8 for the final excavation stage.

Differences in the settlement magnitudes are due to different responses of the applied models to the nodal force reduction. Thus a quantitative comparison between them is not possible. Nevertheless, a remarkable rebound (heave) induced by the soil excavation can be noticed for three models (MC, CC, 3SKH).

Looking at the normalized settlement troughs

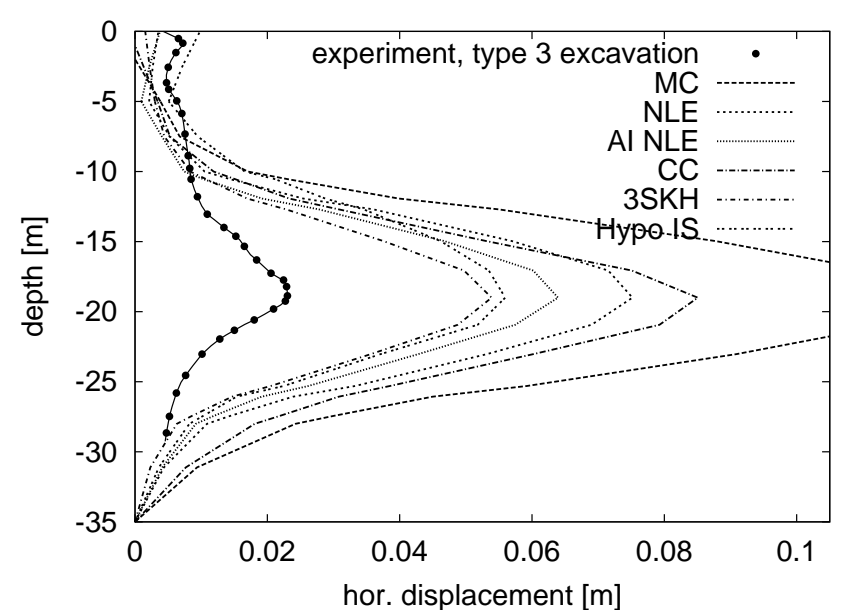

Figure 8. Variation of horizontal deformations $6.3 \mathrm{~m}$ from tunnel centreline with depth at final stage of excavation.

at the final stage of tunnel excavation (Figure 9), we can again distinguish two different groups of models: MC, CC and partially $3 \mathrm{SKH}$ predict a relative surface heave at the tunnel centreline whereas NLE, AI NLE and Hypo IS yield the maximum settlement at this section. Obviously, the models of the first group suffer from the extensive elastic range having stiffness insufficently sensitive to deformation whereas the behaviour from the second group corresponds to the field observations ("experiment" in Figure 9). Besides, the width of the settlement trough predicted by Hypo IS and AI NLE approaches the measured one. This coincides with calculations published by Addenbrooke et al. (1997) - they concluded that adding anisotropy to a strongly non-linear elastic model can produce realistic shapes of the settlement trough. Both phenomena are already embedded in the Hypo IS model.

A more detailed insight into the deformational behaviour can be obtained from the distribution of displacements in layers overlying the tunnel. Figure 10 depicts the experimentally observed contour lines of vertical and horizontal displacements at the final stage of tunnel excavation. Similarly like a narrow shape of the settlement trough, the contour lines of vertical displacements constitute rather slender "drops" which would eventually develop a typical cave-in in case of failure.

The calculated contour lines of vertical displacements in Figure 11 make once more clear that only the simulations with AI NLE and Hypo IS models come close to the observed pattern of deformations (only qualitative comparison is done due to different scales in Figures 10 and 11). Other models fail to capture the typical phenomenon of a limited extent of deformations.

\section{CONCLUSIONS}

The numerical simulations of the tunnel excava- 

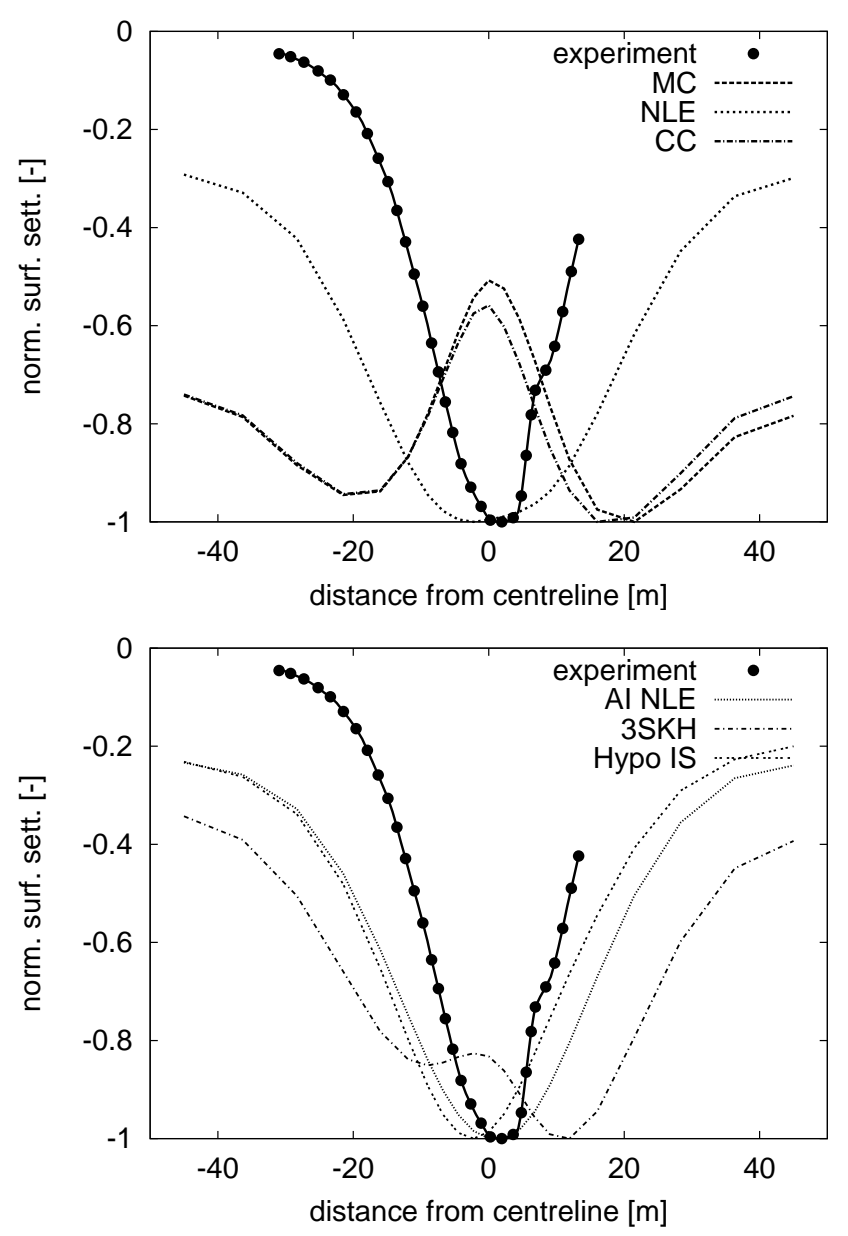

Figure 9. Normalised surface settlement troughs predicted by different constitutive models at final stage of excavation.

tion in London clay have shown that a realistic prediction of deformations is possible only if the applied constitutive model for soil takes into account some basic phenomena (see also Herle, 2003):

- A pronounced non-linearity of the stressstrain curve with a high initial stiffness (cf. Gunn, 1993).

- Anisotropic behaviour with different response in at least two perpendicular directions (cf. Addenbrooke et al., 1997).

- Path-dependent stiffness distinguishing at least "loading" and "unloading".

The best results have been obtained using the hypoplastic model with intergranular strains which covers all three effects. Surprisingly, the advanced 3-SKH model (combined isotropic and kinematic hardening plasticity) does not perform so well, probably due to an unsatisfactory behaviour in the small strain region. The outputs from the cross-anisotropic non-linear elastic model with the Mohr-Coulomb failure criterion confirm that even relatively simple models can yield good results if applied in suitable problems.

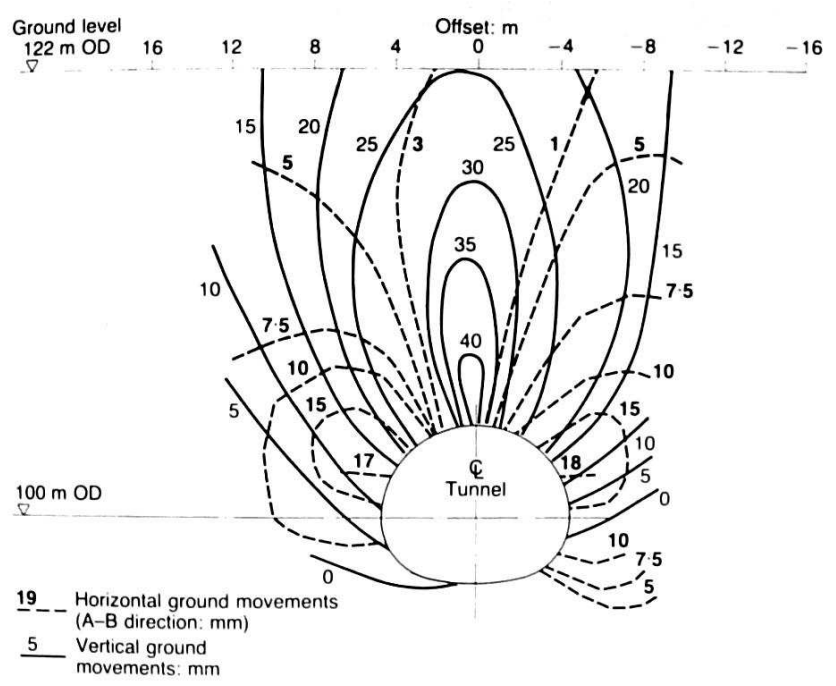

Figure 10. Measured contour lines of vertical and horizontal displacements at the final stage of excavation (Deane and Basset, 1995).

\section{ACKNOWLEDGEMENT}

The first author is grateful for the financial support by the research grants SSPI-CT-2003501837-NOAH'S ARK under the EC $6^{\text {th }} \mathrm{FP}$ and GACR 205/03/1467.

\section{REFERENCES}

Addenbrooke, T. I., Potts, D. M. \& Puzrin, A. M. 1997. The influence of pre-failure soil stiffness on the numerical analysis of tunnel construction. Géotechnique 47(3): 693-712.

Clayton, C. \& Heymann, G. 2001. Stiffness of geomaterials at very small strains. Géotechnique 51(3): 245255.

Cotecchia, F. \& Chandler, J. 2000. A general framework for the mechanical behaviour of clays. Géotechnique 50(4): 431-447.

Deane, A. P. \& Basset, R. H. 1995. The Heathrow express trial tunnel. Proc. Instn. Civil Engineers 113: 144156.

Graham, J. \& Houlsby, G. T. 1983. Anisotropic elasticity of a natural clay. Géotechnique 33(2): 165-180.

Gunn, M. J. 1993. The prediction of surface settlement profiles due to tunnelling. Predictive Soil Mechanics, 304-316.

Herle, I. 2003. Constitutive models for numerical simulations. Rational Tunnelling. Advances in Geot. Eng. and Tunnelling, D. Kolymbas (Ed.), Vol. 8, 27-60.

Herle, I. \& Kolymbas, D. 2004. Hypoplasticity for soils with low friction angles. Computers and Geotechnics 31: 365-373.

Mašín, D. 2003. A kinematic hardening critical state model for anisotropic clays. In Const. Model. and Anal. of Bound. Val. Probl. in Geot. Eng., Napoli, Italy, 253-263.

Mašín, D. 2004. Laboratory and numerical modelling of natural clays. MPhil Thesis, City University, London.

Mašín, D. 2005. A hypoplastic constitutive model for clays. Int. J. Numer. Analyt. Methods in Geomechanics 29(4): 311-336. 

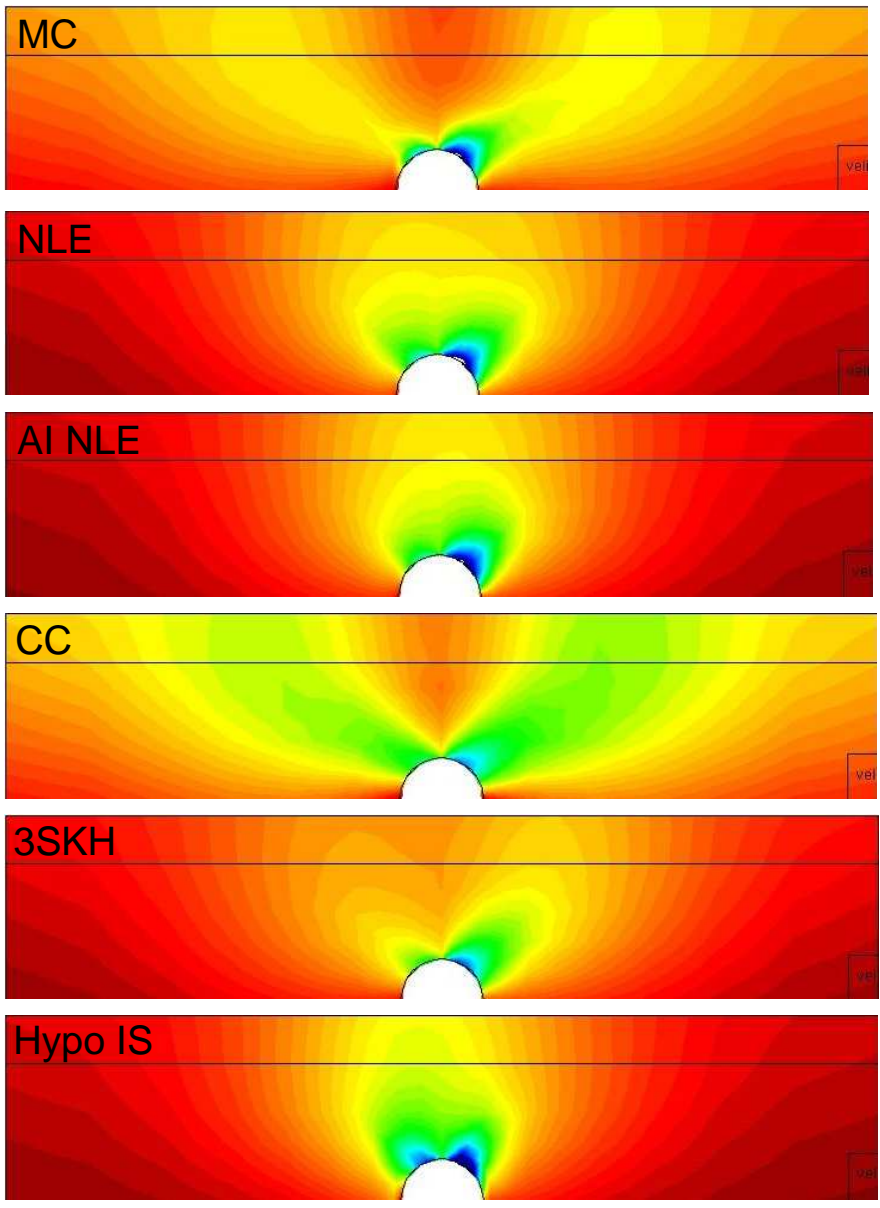

Figure 11. Contour lines of vertical displacements calculated by different models at the final stage of excavation.

Niemunis, A. \& Herle, I. 1997. Hypoplastic model for cohesionless soils with elastic strain range. Mechanics of Cohesive-Frictional Materials 2: 279-299.

Roscoe, K. H. \& Burland, J. B. 1983. On the Generalised Stress-Strain Behaviour of Wet Clay. In Engineering Plasticity, Heyman, J. \& Leckie, F. A. (eds), Cambridge: Cambridge University Press, 535-609.

Stallebrass, S. E. \& Taylor, R. N. 1997. Prediction of ground movements in overconsolidated clay. Géotechnique 47(2): 235-253.

\section{APPENDIX}

Herein, a summary of material parameters for all models is given. The calibration was performed using element tests on London clay.

Table 1. Mohr-Coulomb model.

\begin{tabular}{lllll}
\hline$E$ & $\nu$ & $\phi$ & $\mathrm{c}$ & $\psi$ \\
{$[\mathrm{kPa}]$} & {$[-]$} & $\left.{ }^{\circ}\right]$ & {$[\mathrm{kPa}]$} & {$\left[^{\circ}\right]$} \\
12365 & 0.237 & 22.56 & 0 & 11.28 \\
\hline
\end{tabular}

Table 2. Non-linear elastic model (isotropic). MohrCoulomb failure criterion parameters equal to MC model.

\begin{tabular}{llllll}
\hline$A$ & $n$ & $\kappa^{*}$ & $R$ & $\gamma$ & $\delta$ \\
{$[-]$} & {$[-]$} & {$[-]$} & {$[-]$} & {$[-]$} & {$[-]$} \\
457 & 0.71 & 0.006 & $10^{-4}$ & 0.45 & 0.3 \\
\hline
\end{tabular}

Table 3. Non-linear elastic model (cross-anisotropic). Mohr-Coulomb failure criterion parameters equal to MC model.

\begin{tabular}{lllllll}
\hline$A$ & $n$ & $\kappa^{*}$ & $R$ & $\gamma$ & $\delta$ & $\alpha$ \\
{$[-]$} & {$[-]$} & {$[-]$} & {$[-]$} & {$[-]$} & {$[-]$} & {$[-]$} \\
457 & 0.71 & 0.006 & $10^{-4}$ & 0.4 & 0.25 & 1.5 \\
\hline
\end{tabular}

Table 4. Modified Cam-Clay model.

\begin{tabular}{lllll}
\hline $\mathrm{G}$ & $\mathrm{M}$ & $\kappa$ & $\lambda$ & $N$ \\
{$[\mathrm{MPa}]$} & {$[-]$} & {$[-]$} & {$[-]$} & {$[-]$} \\
5 & 0.88 & 0.066 & 0.253 & 3.724 \\
\hline
\end{tabular}

Table 5. 3-SKH model.

\begin{tabular}{lllll}
\hline$A$ & $n$ & $m$ & $M$ & $\kappa^{*}$ \\
{$[-]$} & {$[-]$} & {$[-]$} & {$[-]$} & {$[-]$} \\
457 & 0.71 & 0.27 & 0.88 & 0.006 \\
\hline$\lambda^{*}$ & $T$ & $S$ & $\psi$ & $N$ \\
{$[-]$} & {$[-]$} & {$[-]$} & {$[-]$} & {$[-]$} \\
0.11 & 0.24 & 0.16 & 2 & 1.446 \\
\hline
\end{tabular}

Table 6. Hypoplastic model for soils with low friction angles enhanced by the intergranular strain concept.

\begin{tabular}{llllllll}
\hline$\phi_{c}$ & $h_{s}$ & $n$ & $e_{d 0}$ & $e_{c 0}$ & $e_{i 0}$ & $\alpha$ \\
{$\left[^{\circ}\right]$} & {$[\mathrm{kPa}]$} & {$[-]$} & {$[-]$} & {$[-]$} & {$[-]$} & {$[-]$} & \\
22.56 & 655.9 & 0.186 & 3.02 & 3.23 & 3.69 & 0.15 & \\
\hline$\beta$ & $r$ & $p_{\xi}$ & $R$ & $m_{R}$ & $m_{T}$ & $\beta_{r}$ & $\chi$ \\
{$[-]$} & {$[-]$} & {$[-]$} & {$[-]$} & {$[-]$} & {$[-]$} & {$[-]$} & {$[-]$} \\
1 & 0.5 & 0.2 & $10^{-4}$ & 10 & 10 & 0.1 & 6 \\
\hline
\end{tabular}

